\title{
CrimRxiv
}

\section{Vulnerability to \\ radicalisation in a general population: a psychometric network approach}

Caitlin Clemmow, Noemie Bouhana, Zoe Marchment, Paul Gill

Published on: Feb 28, 2022

DOI: $10.21428 / \mathrm{cb} 6 \mathrm{ab} 371.9 \mathrm{fd} 7117 \mathrm{a}$

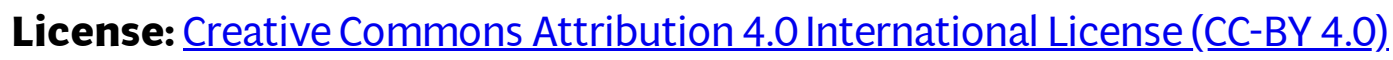


